\title{
CASE OF LOCOMOTOR ATAXY.
}

BY O. F. NEWCOMBE, M.D.,

Late Auiatant Hedical Offioer, Lancaster County Aeylum, Rainhill.

But few cases of Locomotor Ataxy associated with mental disorder have so far been recorded in this country, and the following crse presented fentures differing in many respects from those I heve seen described.

In September 1876, J. K. (single), a Liverpool cotton porter, was brought to the Rainhill Asylum, the medical certificate stating that he was "low-spirited, despondent, obstinate, and taciturn." On examination four days after admission he was found to be in fair bodily condition, of sallow complexion, and with a very melancholy expression. Both his pupils were contracted to a pin's point, and the right was of irregnlar ontline and attached to the cornea. The chest was healthy; his tongue steady and protruded straight; appetite good; urine of dark colour and high specific gravity-no albumen; temperature normal. Patient's gait was jerky, his heel first touching the ground when he put his foot down. With closed eyes he was unable to turn or even to walk without assistance, as he at once began to stagger. Percussion and the application of a hot sponge showed that no single vertebra or skin-area was more tender or sensitive than the rest. On tickling the soles of the feet, reflex action was found to be slow, but much exaggerated when produced. Sensibility in the lower extremities was much diminished.

The patient's account of himself entirely tallied with that contrined in the following extract which Dr. Davidson kindly allowed me to make from his Case Book.

J. M. K., æet. 35, single, porter, admitted into the Northern Hospital, Liverpool, Sept. 18, 1874 (under the care of Dr. Davidson). Patient's complaint is pretty evident, consisting of ataxic symptoms which have the following history.

A bout the middle of January of the present year he first felt his feet cold and a sense of numbness in them; shortly after, he began to experience difficulty in locomotion which made 
him give over work. In abont a month he began to have a springing sensation in the soles of his feet, so that he tended to fall forward, and felt as if he was walking on poultices. About the end of Jankary, when going to church he noticed that he had great difficulty in going up the steps. At present he does not find it much more difficult to come up than go down stairs, if the steps are broad, but when they are narrow he finds the truth of Virgil's line

"Red revocare gradum, enperasque evedere ad enras
Hoo opus, hio labor."

He was several months under modical treatment, and took various patent medicines, such as "Blair's pills," and $£ 5$ worth of Dr. Swedor's “Vital Regenerator." Has had 5 weeks' application of the faradic current applied six times a week for about $\frac{1}{2}$ hour each day. Has also had many salt-water baths.

Previous History.-About 15 years ago he had a chancre and bubo, some months later a gonorrhoea, and shortly afterwards had rheumatic fever. Has nlways otherwise been healthy. Never bad skin eruption, nor alopecia, nor sore throat.

Thinks he has been falling off in flesh of late; at present his muscles are soft and flabby. Height about $5 \mathrm{ft} .6$ in., weight never exceeded 10 stone.

Locomotory Bystem. - He walks with feet widely apart, carriea his limbs hurriedly forward and away from the mesial line. In throwing his limbs forward his feet are powerfully extended, the heel being brought rapidly down, and the rest of the foot following with a flapping motion. He can walk pretty well on a base of 10 inches. His locomotor difficulties are increased by closing his eyes, and then when standing he has a swaying movement. He has great muscular power, and can resist with much force any interference with his limbs. His legs when at rest are often affected with irregular involuntary morements, and even the strongest efforts of patient's will are unable to overcome these spasmodic muscular contractions. He can distingnish between heat and cold, but the transmission of thermal impressions is delayed, those of heat being most so; cold is felt from $1 \frac{1}{2}$ to 2 seconds after impression is made, and heat felt about 3 seconds after limb is touched. The tactile sensibility is much diminished in the feet, and even painful impressions atre not acutely felit. There is no special tender spot along the spine, and hot and cold sponges are felt equally throughout.

The muscular power of his arms, as tested by the dynamometer, is good, and in them the power of co-ordination is perfect. Has occasional diplopia, but this followed an injury to and operation on the right eye 20 years ago. His body is marked with small cicatrices, the result of small-pox, which he 
had when 5 years old. Both pupils are greatly contricted and equally so.

Nov. 4th.-Examination of the heart reveals slight roughening with the first sound at the base.

There is some sickness, anorexia, and loose bowels ; pulse 100.

Nov. 9th.-The cardiac phenomena referred to in last note are perhape more distinct to-day. The apex is in fifth interspace, and in line of nipple. Transverse measurement 4 inches.

'I'he cardiac dulness extends up the sternum as high as the junction of the manubrium with the body of the sternum. Over this narrow strip of dulness and at the base there is a roughening of the first sound, of a probably pericurdial origin. 'The second sound is also somewhat harsh and prolonged.

Appetite bad, bowels rather loose, pulse weak.

Nov. 28th.-Patient feels anxious to leave to-day, and consequently is discharged.

After leaving the hospital he again tried the effects of galvanism and remedies prescribed by herbalists and others, to whom he despairingly applied for relief, but at last, finding his case considered a hopeless one, he seems to have fallen into a despondent state of mind, his temper become irritable and suspicions, and finally his friends had to remove him to the workhouse on account of his obstinacy and general unmanageableness.

$\mathrm{He}$ related his story slowly, in plaintive, melnncholy tones, but without hesitation or tremor of the voice; appeared to have a good memory for the dates and details of both recent and remote occurrences, and when roused answered all questions readily and accurately, although when left to himself he was always absorbed in the contemplation of his own ailments.

In October it was noted that he was still very depressed and fond of solitude, that he had frequent outbursts of crying and sobbing, and at times expressed great alarm lest custration should be practised as a remedy for his disease. Nocturnal emissions oocurred frequently. Patient wrote several times to his friends, his writing being of average firmness, his letters well formed and no words omitted. He had great power in his arms, and made himself useful by blacking all the boots in his ward. About a month later he complained of the pains and aches in his lower limbs being much worse; and attributed them to the action of workmen in the ward who "were killing him with their raps and taps." At night he occasionally became violent, the snoring of his neighbours sounding in his ears as the voices of "Roman Catholics telling him to curse his Queen and the Protestant religion."

For mauy montlis after this his mental condition remained stationary, although his bodily symptoms were steadily pro- 
gressing. He complained of double vision, though the axes of his eyes were to all appearance parallel. He began to have suspicions as to his food being drugged, and frequently struck other patients, nnder the idea that the shocks and sturts he felt in his extremities were crused by them. In September 1877 , on three several occasions while he was sitting quietly on his chair, his legs became strongly convulsed without any previous.warning, causing him to fall on the floor, where he lay for two or three minutes on his back, ineffectually endeavouring to check the extravagant movements of his limbs: His articulation had now become slower and rather tremulous, but mastication and deglutition were well performed. His handwriting remained firm and distinct, but words and letters were omitted. Double vision had censed; but his sight grew much wesker. His pupils continued, as from the first, minutely contracted. He complained of having to micturate very frequently, but retained fall control over his sphincters. Attacks of emotional excitement grew more numerous and prolonged, and often occurred when he was alone. $\mathrm{He}$ also held long conversations with imaginary personages, who used, he said, very bad language. At the beginning of the present year he began to lose flesh and to grow weaker; his memory was much more impaired; he appeared to be entirely engrossed in himself ; his tones were more querulous, and he used to complain that twenty ounces of chloroform were given him by the night attendant every night. The fulminating pains were as strong as ever, but sensibility in his lower extremities had decreased, and, although ho was quite unable to walk without steadying himself by walls and furniture, and even when his feet flew out laterally to the danger of passers by, his hands and arms were still only affected to a very slight degree. In March he was found to be very much weaker; he had retention with incontinenoe of highcolonred ammoniacal urine, which had to be regularly drawn off, when he complained that French semen was being substitnted for his own. Introduction of the catheter was al ways painful. Speech wus more affected, swallowing at times difficult.

From this time until his death on April 16th, 1878, ho rupidly lost flesh, but was ulways able to feed and raise himself. Flexion of his lower limbs could be resisted with some power until the day before his denth. Whenever the weight of the bed-clothes was taken off his legs strong spasmodic jerking commenced, and was continued nntil the clothes were replaced. The tenperatare in the axilla, which had averaged about $100^{\circ}$ for some days, did not rise to any great extent before his death, and his lungs remained fairly healthy.

At the autopsy, made twenty-seven hours ufter deatb, the 
body was found to be much emaciated. The calvarium was dense, and the dura mater adherent to it. The arachnoid was slightly thickened, the vessels of the pia mater nearly empty. The membranes were adherent only over the tips of the temporo-sphenoidal lobes. There was some wasting of the convolntions bordering on the fissure of Rolando, and a large quantity of fluid escapod on removal of the membranes and on opening the ventricles. The lining membrane of the lateral ventricles was granular, the arteries at the base of the brain normal. The brain substance was firm and healthy-looking, and the weight of the whole organ fifty-four ounces. On examination of the recent spinal cord, the pia mater was found to be congested; the cord itself wasted, and of a dirty greyish hue on removal of the membranes. On section extensive grey degeneration was distinctly seen in the posterior regions, especinlly in the lower dorsal and the lumbar portions of the cord.

On microscopical examination of sections made by Dr. Ashby, of the Liverpool School of Medicine, after hardening in bichromate of ammonia, the nsual changes of the structure of the cord were seen, but in a very advanced stage. Corpora amylacen were numerous; and the large multipolar cells of the posterior cornua of grey matter had almost disappeared in the fower part of the cord, while those in the anterior were much diminished in size and number.

Remarks.-It was pointed out by Dr. Nichol, in the first volume of the 'West Riding Asylum Medical Reports,' that the mental symptoms accompanying locomotor ataxy are, in the large majority of instances, marked by delusions of an exalted character, and in six out of the eight cases he describes, or quotes, these were present. In the case of J. McK., however, there seems to have been no period during which he experienced pleasurable emotions dependent upon the feeling of power. On the contrary, great depression due to the sense of growing weakness characterised his history throughout.

Most of his hallucinations and delusions, too, were apparently due to perverted sensations; the brain receiving abnormal impressions from and through the diseased sensorytracts, and referring them wrongly to peripheral influences.

In addition to the slight nature of the ehanges that were discoverable in the brain itself, it is, worthy of remark that this organ weighed nine ounces more than the average weight of the brain in 197 cases of general paralysis, and ten ounces more than the average weight of the brain in 700 cases of all varieties of insanity, as recorded by $\mathrm{Mr}$. Crochley Clapham, in vol. vi. 'West Riding Asylum Medical Reports.' 'The Wcight of the Brain in the Insane,' by C. Clapham, L.R.C.P., \&c. 